\title{
Quantity and quality profiles of antibiotics pre, on, and post surgery in a hospital setting
}

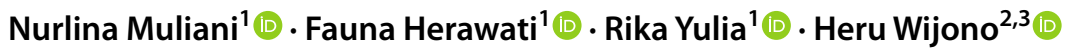 \\ Received: 18 July 2020 / Accepted: 16 February 2021 \\ (c) The Author(s), under exclusive licence to Springer Nature Switzerland AG part of Springer Nature 2021
}

\begin{abstract}
Background Providing proper antibiotics is undoubtedly crucial to prevent infections during surgery. Objective This study set out to evaluate the medication administration in antibiotic prophylaxis using both quantitative and qualitative methods. Setting The study employed a retrospective design and observed patients who underwent surgical procedures during hospitalization at a private hospital in Indonesia within the period of January-June 2019. Methods The data obtained were evaluated quantitatively and qualitatively; and analyzed descriptively. The quantitative evaluation used the defined daily dose (DDD) per 100 bed-days. The qualitative evaluation was expressed as the percentage of antibiotic suitability based on antibiotic administration, i.e. (1) type; (2) timing; (3) dosage; (4) duration; and (5) route. Main outcome measure Suitability of antibiotic prophylaxis in a hospital setting. Results There were 164 prescriptions recorded from 20 types of surgical procedures, of which the most common was cholecystectomy (23 patients, $14 \%$ ). Most antibiotics were administered 61-120 min before the incision time (55 patients, 37\%), and had a duration of more than $24 \mathrm{~h}$ (119 patients, $80 \%)$. The total DDD per 100 bed-days for pre-, on-, and post-surgery antibiotic use were 44.2,33.3, and 66.7 respectively. The suitability profiles of the antibiotics used according to the Antibiotic Use Guideline for Hospital (2018) were as follows: 26.3\% right type, 52.9\% right time, 24.8\% right dosage, 19.1\% right duration, 91.8\% right route, while according to American Society of Health-System Pharmacists Therapeutic Guidelines (2014) there were 17.6\% right type, 53.4\% right time, $16.4 \%$ right dosage, $19.1 \%$ right duration, and $96.6 \%$ right route. Conclusion Ceftriaxone was the first-choice prophylactic antibiotic administered in this Indonesian hospital. The data indicate a considerable non-compliance with local and international guidelines.
\end{abstract}

Keywords Antibiotic prophylaxis $\cdot$ DDD per 100 bed-days $\cdot$ Inappropriate prescriptions $\cdot$ Surgery

\section{Impacts on practice}

- Evaluating antibiotic prophylaxis is useful for assessing the possibility of inappropriate antibiotic use.

- Surgeons tend to prescribe prophylactic antibiotics for all types of surgery despite the absence of prerequisites for some of them.

Rika Yulia

rika_y@staff.ubaya.ac.id

1 Faculty of Pharmacy, University of Surabaya, Jl. Raya Kalirungkut, Surabaya, East Java, Indonesia 60284

2 Husada Utama Hospital Surabaya, Surabaya, Indonesia

3 Faculty of Medicine, University of Surabaya, Surabaya, Indonesia
- Frequent inappropriate use of antibiotics can increase the cost of treatment and antibiotic resistance in patients.

- Increasing adherence to guidelines and the use of appropriate prophylactic antibiotics are important points in prevention of surgical site infection and control of microbial resistance.

- To increase adherence, training is needed to normalize antibiotic selection in accordance with international and local guidelines.

\section{Introduction}

The National Institute for Health and Care Excellence [1] indicates prophylactic antibiotics in clean, clean-contaminated, and contaminated surgeries, but therapeutic antibiotics for procedures with dirty or infected surgical wounds. Therapeutic antibiotics are used to eradicate or inhibit the growth 
of suspected or proven bacteria whilst prophylactic antibiotics are given to prevent infection in patients with high-risk procedures, and the target of their administration is to reduce the number of bacteria present and help the natural defenses of the host so that no infection occurs [2-4]. Most antibiotic prophylaxis, including the use of cefazolin, is recommended $30-60 \mathrm{~min}$ before incision $-2 \mathrm{~h}$ if vancomycin or a fluoroquinolone is used-to ensure that the presence of antibiotics in serum and tissue can reach the target during the surgery $[5,6]$.

The Hospital National Antimicrobial Prescribing Survey (2020) analyzed 26,714 prescriptions from 324 hospitals in Australia and found that inappropriate prophylactic antibiotic prescriptions in surgical patients was the highest of the 20 most common indications, such as community-acquired pneumonia, medical prophylaxis, cystitis, and cellulitis/ erysipelas. In that study, use of surgical prophylactic prescriptions for more than $24 \mathrm{~h}$ decreased over six years, from $41.1 \%$ in 2013 to $28.0 \%$. The most common reasons for inappropriate prescriptions include: spectrum too broad (23.7\%), incorrect dose or frequency (20.3\%), and incorrect duration $(20.0 \%)[7,8]$.

Inappropriate antibiotic therapy, including excessive use of antibiotics, inappropriate dosages, and prolongation of therapy, potentially results in problems, such as the emergence of microorganisms resistant to some antibiotics. Antibiotic resistance makes treating the cause of infection increasingly difficult and causes prolonged illness, treatment, and hospital stay, loss of protection for patients undergoing surgery and other medical procedures, and increased costs and mortality [9-12].

The use of antibiotics in preventing infections is essential to reduce the risks associated with surgery and resistance. For this reason, maximizing the quality of prophylactic antibiotic prescribing for surgery and antibiotic therapy (to treat existing infections) requires a appropriate strategy. In Indonesia, to control the incidence of resistance in hospitals, the Minister of Health has issued Regulation No. 8 (2015) on the Antimicrobial Resistance Control Program in Hospitals [13-16]. Judicious antibiotic use includes monitoring antibiotic use patterns and antibiotic resistance patterns. As an attempt to evaluate the type and amount of antibiotics, antibiotic use patterns can be assessed quantitatively by calculating Anatomical Therapeutic Chemical/Defined Daily Dose (ATC/DDD) per 100 bed-days; these patterns can also be determined qualitatively to evaluate the suitability of antibiotic use by analyzing the appropriateness of indications, timing, dose, duration, and route of administration $[11,14,15]$.

\section{Aim of the study}

This study was designed to evaluate the use of prophylactic antibiotics in surgical patients quantitatively and qualitatively.

\section{Ethics approval}

This retrospective study involving human participants was in accordance with the ethical standards of the institutional ethical committee University of Surabaya with the Ethics Agreement No. 109/KE/XI/2019.

\section{Methods}

\section{Study design}

The study employed a retrospective design and observed patients who underwent surgical procedures during hospitalization at a private hospital in Surabaya within the period of January-June 2019. Surgical procedures are commonly categorized by: (A) degree of urgency, (B) the seriousness of surgery, (C) the field of surgery, (D) type of surgery.

(A) Degree of urgency: (1) elective surgery: is a planned operation that can be ordered in advance as a result of a surgeon's judgment. (2) emergency surgery: surgery to treat trauma or acute illness in patients who come to the emergency department, or surgery which is not planned for patients being treated in other ways, or patients who have been waiting for elective surgical procedures.

(B) The seriousness of surgery: (1) major, (2) intermediate, and (3) minor. The category is determined by the surgeon in the hospital. Generally: major surgeries are usually extensive and require overnight treatment or an extended stay in the hospital. These operations include extensive work such as entering body cavities, removing organs, or changing anatomy. Minor surgeries are generally superficial and do not require penetration of a body cavity.

(C) The field of surgery: including orthopedic, ocular, neurosurgery, cardiac, surgical oncology, and general surgery.

(D) Type of surgery: (1) clean surgery: operations performed on areas without pre-surgical infection, without opening the tract (respiratory, gastrointestinal, urinary, biliary), planned surgery, or primary skin closure with or without the use of closed drains. (2) clean-contaminated surgery: operations performed on the tract (digestive, biliary, urinary, respiratory, reproductive except 
for the ovaries) or surgeries without significant contamination. (3) contaminated surgery: operations that open the gastrointestinal tract, bile duct, urinary tract, airway to the oropharynx, reproductive tract except for the ovaries with real contamination (gross spillage) [15, 18-20].

The inclusion criteria included patients aged $\geq 18$ years who had complete inpatient medical records, including diagnosis, surgery, length of stay, name of drug, dosage, and the number of antibiotics used. The exclusion criteria were (1) surgical patients who had to undergo Intensive Care Unit (ICU) treatment, (2) patients who had an infection before a surgical procedure, and (3) patients who were discharge against medical advice or died during the period of the study.

The use of antibiotics was classified into three stages, namely pre-, on-, and post-surgery. Here, pre-surgery represents the antibiotic given before the day of surgery, on-surgery includes the antibiotic given on the day of surgery-i.e., $120 \mathrm{~min}$ before to $<24 \mathrm{~h}$ after surgery, and post-surgery is where the antibiotic was administered $>24 \mathrm{~h}$ after surgery.

The use of antibiotics is classified into $0,1,2,3$ antibiotics where 0 means not using antibiotic, 1 using one antibiotic, 2 using a combination of two antibiotics, and 3 using a combination of three antibiotics.

\section{Data analysis}

The data obtained were then evaluated quantitatively and qualitatively and analyzed descriptively. The quantitative evaluation used the DDD per 100 bed-days, which was calculated using the formula below:

$\frac{D D D}{100}$ bed-days $=\frac{\text { total antibiotics }(\text { gram }) \times 100}{D D D W H O(\text { gram }) \times L O S}$

where DDD WHO, defined daily dose determined by WHO; LOS, total length of stay.

The qualitative evaluation was expressed as the percentage of antibiotic suitability based on antibiotic administration characteristics, namely (1) type; (2) timing; (3) dosage; (4) duration; and (5) route, and the comparison with Antibiotic Use Guideline in Hospital and American Society of Health-System Pharmacists (ASHP) Therapeutic Guidelines $[6,17,19]$.

The research results were analyzed descriptively. The total DDD and percentage of antibiotic suitability are reported in tables.

\section{Results}

There were 708 surgical patients from January to June 2019, but only 164 patients met the inclusion and exclusion criteria and had medical records available (Fig. 1). Table 1 illustrates

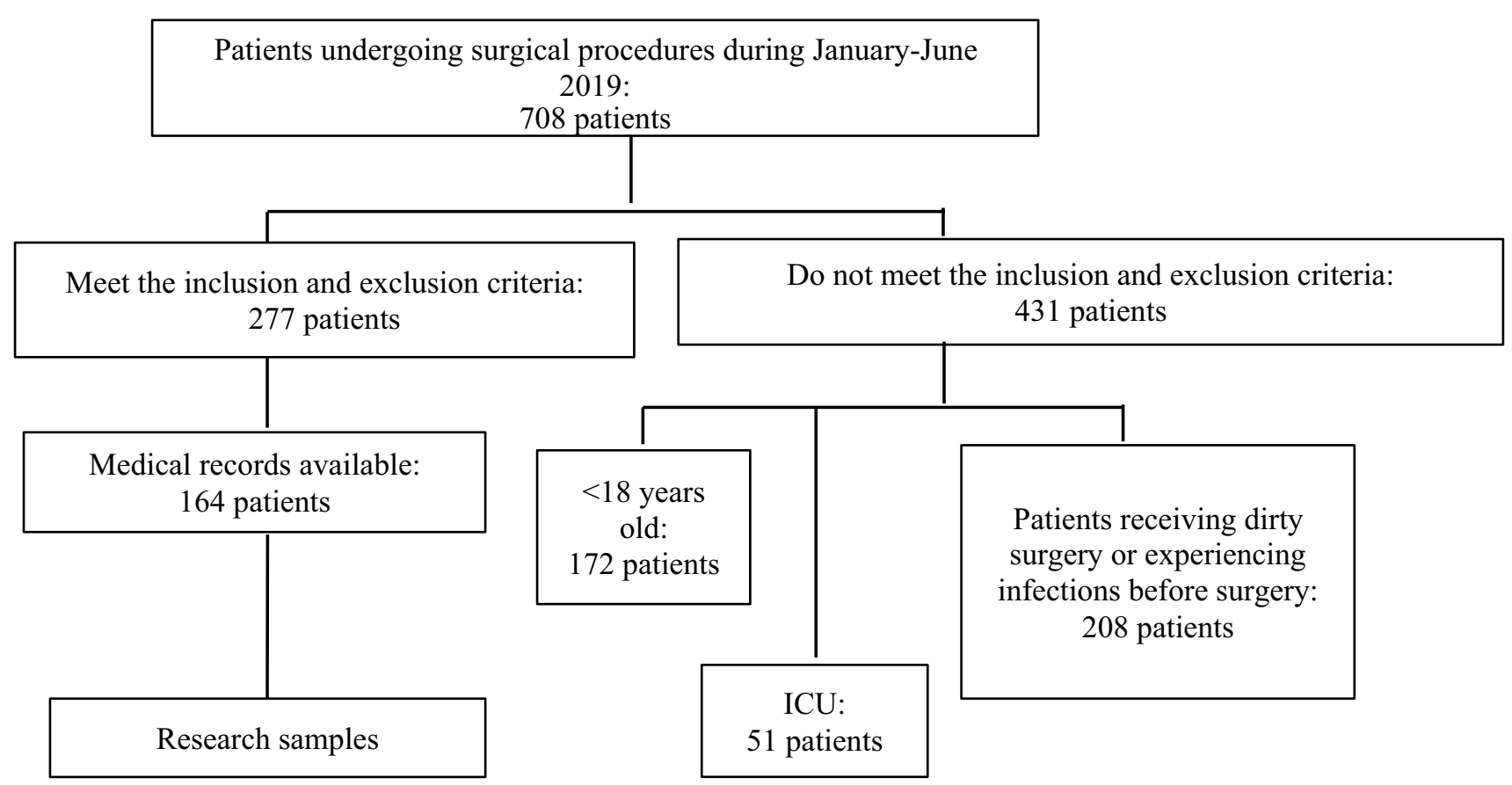

Fig. 1 The flowchart of the research data collection. ICU Intensive Care Unit 
Table 1 The demographic characteristics of the research samples

\begin{tabular}{|c|c|c|c|c|c|c|c|c|}
\hline Characteristics & Jan 2019 & Feb 2019 & Mar 2019 & Apr 2019 & May 2019 & Jun 2019 & Total & $\%$ \\
\hline \multicolumn{9}{|l|}{ Age (years) } \\
\hline $18-25$ & 3 & 1 & 4 & 1 & 1 & 4 & 14 & 8 \\
\hline $26-35$ & 7 & 4 & 4 & 7 & 8 & 4 & 34 & 21 \\
\hline $36-45$ & 6 & 10 & 8 & 5 & 6 & 2 & 37 & 23 \\
\hline $46-55$ & 8 & 5 & 10 & 4 & 3 & 5 & 35 & 21 \\
\hline $56-65$ & 4 & 4 & 3 & 1 & 4 & 4 & 20 & 12 \\
\hline$\geq 65$ & 3 & 5 & 2 & 6 & 4 & 4 & 24 & 15 \\
\hline Mean \pm SD & $44.61 \pm 15.38$ & $47.86 \pm 13.73$ & $42.87 \pm 13.56$ & $47.38 \pm 17.13$ & $44.92 \pm 15.45$ & $45.33 \pm 18.03$ & $45.50 \pm 1.85$ & \\
\hline Total & 31 & 29 & 31 & 24 & 26 & 23 & 164 & 100 \\
\hline \multicolumn{9}{|l|}{ Gender } \\
\hline Male & 15 & 8 & 9 & 13 & 9 & 7 & 61 & 37 \\
\hline Female & 16 & 21 & 22 & 11 & 17 & 16 & 103 & 63 \\
\hline Total & 31 & 29 & 31 & 24 & 26 & 23 & 164 & 100 \\
\hline \multicolumn{9}{|l|}{$\begin{array}{l}\text { Status of } \\
\text { hospital bill } \\
\text { payment }\end{array}$} \\
\hline Private & 18 & 15 & 17 & 15 & 10 & 10 & 85 & 52 \\
\hline BPJS & 13 & 14 & 14 & 9 & 16 & 13 & 79 & 48 \\
\hline Total & 31 & 29 & 31 & 24 & 26 & 23 & 164 & 100 \\
\hline
\end{tabular}

Jan January, Feb February, Mar March, Apr April, Jun June, SD standard deviation, BPJS Badan Penyelenggara Jaminan Sosial (Indonesia's Healthcare and Social Security Agency)

the demographic information of these patients. All patients had four categories of surgeries, they were divided into with number of groups. There were 20 types of surgical procedures, of which the five most common types were cholecystectomy (23 patients, 14\%), herniotomy (18 patients, 11\%), arteriovenous (AV) shunt (18 patients, $11 \%$ ), appendectomy (17 patients, $10 \%$ ), and myomectomy (14 patients, $9 \%$ ). $97 \%$
(159) were elective surgeries, and $41 \%$ (81) were major surgeries. 57\% (94) were rated as clean surgeries. See Table 2 for details.

Table 3 illustrates the profile of patients based on the number, timing, interval, and duration of antibiotic use. Most patients $(129,79 \%)$ received a single antibiotic. Fifty-five patients (37\%) that antibiotics were administered

Table 2 Profiles of research samples based on the surgical procedure

\begin{tabular}{lrrrrrrrr}
\hline Characteristics & Jan 2019 & Feb 2019 & Mar 2019 & Apr 2019 & May 2019 & Jun 2019 & Total & $\%$ \\
\hline $\begin{array}{l}\text { Degree of urgency } \\
\text { Elective }\end{array}$ & 31 & 28 & 29 & 24 & 26 & 21 & 159 & 97 \\
Emergency & 0 & 1 & 2 & 0 & 0 & 2 & 5 & 3 \\
Total & 31 & 29 & 31 & 24 & 26 & 23 & 164 & 100 \\
The seriousness of surgery & & & & & & & & \\
Minor & 0 & 8 & 3 & 0 & 0 & 0 & 11 & 7 \\
Intermediate & 11 & 8 & 14 & 5 & 9 & 2 & 49 & 30 \\
Major & 13 & 8 & 10 & 15 & 15 & 20 & 81 & 49 \\
Complex & 7 & 5 & 4 & 4 & 2 & 1 & 23 & 14 \\
Total & 31 & 29 & 31 & 24 & 26 & 23 & 164 & 100 \\
The field of surgery & 14 & 19 & 22 & 12 & 13 & 14 & 94 & 57 \\
Clean & 15 & 9 & 8 & 12 & 12 & 9 & 65 & 40 \\
Clean-contaminated & 2 & 1 & 1 & 0 & 1 & 0 & 5 & 3 \\
Contaminated & 31 & 29 & 31 & 24 & 26 & 23 & 164 & 100 \\
Total & & & & & & & & \\
\hline
\end{tabular}

Jan January, Feb February, Mar March, Apr April, Jun June 
Table 3 Profiles of the research samples based on the use of antibiotics

\begin{tabular}{|c|c|c|c|c|c|c|c|c|}
\hline Characteristics & Jan 2019 & Feb 2019 & Mar 2019 & Apr 2019 & May 2019 & Jun 2019 & Total & $\%$ \\
\hline \multicolumn{9}{|c|}{ Number of antibiotic uses } \\
\hline 0 Antibiotic & 3 & 7 & 3 & 1 & 0 & 1 & 15 & 9.15 \\
\hline 1 Antibiotic & 23 & 21 & 24 & 20 & 24 & 18 & 130 & 79.26 \\
\hline 2 Antibiotics & 5 & 1 & 3 & 3 & 2 & 4 & 18 & 10.98 \\
\hline 3 Antibiotics & 0 & 0 & 1 & 0 & 0 & 0 & 1 & 0.61 \\
\hline Total & 31 & 29 & 31 & 24 & 26 & 23 & 164 & 100 \\
\hline \multicolumn{9}{|c|}{ Timing of antibiotic use } \\
\hline Pre surgery & 0 & 0 & 0 & 0 & 0 & 0 & 0 & 0 \\
\hline On surgery & 7 & 6 & 13 & 0 & 0 & 4 & 30 & 20 \\
\hline Post surgery & 0 & 0 & 0 & 0 & 0 & 0 & 0 & 0 \\
\hline Pre-on surgery & 0 & 0 & 0 & 0 & 0 & 0 & 0 & 0 \\
\hline On-post surgery & 19 & 15 & 11 & 15 & 25 & 17 & 102 & 69 \\
\hline Pre-on-post surgery & 2 & 2 & 4 & 8 & 1 & 0 & 17 & 11 \\
\hline Total & 28 & 23 & 28 & 23 & 26 & 21 & 149 & 100 \\
\hline \multicolumn{9}{|c|}{ Interval of antibiotic use } \\
\hline $0-30 \mathrm{~min}$ & 11 & 4 & 5 & 7 & 3 & 5 & 35 & 24 \\
\hline $31-60 \mathrm{~min}$ & 4 & 1 & 5 & 8 & 7 & 7 & 32 & 21 \\
\hline $61-120 \min$ & 9 & 10 & 12 & 6 & 10 & 8 & 55 & 37 \\
\hline$>120 \min$ & 4 & 8 & 6 & 2 & 6 & 1 & 27 & 18 \\
\hline Total & 28 & 23 & 28 & 23 & 26 & 21 & 149 & 100 \\
\hline \multicolumn{9}{|c|}{ Duration of antibiotic use } \\
\hline$<24 \mathrm{~h}$ & 7 & 6 & 13 & 0 & 0 & 4 & 30 & 20 \\
\hline$>24 \mathrm{~h}$ & 21 & 17 & 15 & 23 & 26 & 17 & 119 & 80 \\
\hline Total & 28 & 23 & 28 & 23 & 26 & 21 & 149 & 100 \\
\hline
\end{tabular}

Jan January, Feb February, Mar March, Apr April, Jun June, min minutes, $h$ hours

Table 4 Quantities of antibiotic use within the period of January-June 2019

\begin{tabular}{llllllc}
\hline No & ATC code & Antibiotics & \multicolumn{2}{c}{ DDD per 100 bed-days } & \multirow{2}{*}{$\begin{array}{c}\text { Total DDD per } \\
\text { 100 bed-days }\end{array}$} \\
\cline { 5 - 6 } & & & DDD pre & DDD on & DDD post & \\
\hline 1 & J01CA04 & Amoxicillin & - & - & 0.72 & 0.72 \\
2 & J01DB04 & Cefazolin & 0.74 & 2.82 & 1.55 & 5.11 \\
3 & J01DD01 & Cefotaxime & - & 0.04 & 0.04 & 0.08 \\
4 & J01DD02 & Ceftazidime & - & 0.14 & - & 0.14 \\
5 & J01DD04 & Ceftriaxone & 14.71 & 22.57 & 38.34 & 75.62 \\
6 & J01DD62 & Cefoperazon sulbactam & 12.26 & 3.06 & 10.17 & 25.49 \\
7 & J01DE01 & Cefepime & 1.47 & 0.14 & 1.45 & 3.06 \\
8 & J01DH02 & Meropenem & 14.34 & 1.59 & 4.94 & 20.87 \\
9 & J01GB03 & Gentamicin & - & - & 0.17 & 0.17 \\
10 & J01MA12 & Levofloxacin & - & 0.14 & 0.64 & 0.78 \\
11 & J01XD01 & Metronidazole & 0.74 & 2.82 & 8.63 & 12.19 \\
Total & & & 44.24 & 33.31 & 66.67 & 144.22 \\
\hline
\end{tabular}

$D D D$ defined daily dose 
61-120 min before the incision time. Thirty patients (20\%) that antibiotics were administered on the day of surgery only, 102 patients (69\%) that antibiotics started on the day but continued afterward; and 119 patients $(80 \%)$ had more than $24 \mathrm{~h}$ duration of antibiotics.

The total DDD per 100 bed-days for pre-, on-, and postsurgery antibiotics use, were 44.2,33.3, and 66.7. Table 4 summarizes the DDD for each antibiotic used. Eleven different antibiotics were used in prophylaxis in this study, of which ceftriaxone was the most commonly used with 75.6 DDD/100 bed-days.

Qualitatively, the percentage of suitability was evaluated by comparing not only the antibiotic selection but also the timing, dosage, duration, and route of antibiotic administration described in Antibiotic Use Guideline Hospital and ASHP Therapeutic Guidelines. Table 5 presents the summarized results of the suitability of the antibiotic use.

\section{Discussion}

\section{The quantitative evaluation}

The quantitative evaluation of antibiotic use using DDD/100 bed-days as a measurement unit was intended to identify antibiotic use patterns: a high DDD indicates frequent antibiotic use. In this study, ceftriaxone was the most commonly used antibiotic with 75.6 DDD/100 bed-days, meaning that for 100 days of treatment at the hospital, about 76 patients received one ceftriaxone DDD daily. This figure is higher than a cross-sectional retrospective study that involved 463 surgical patients at a University Hospital in Surabaya that found the use of ceftriaxone for prophylaxis at 21.1 DDD/100 days of surgery [21]. The high DDD/100 bed-days for the administration of ceftriaxone can indicate an inappropriate antibiotic selection because based on ASHP Therapeutic Guidelines, the first-choice antibiotic for most surgical procedures in USA is cefazolin $[6,22]$. However, the most common infecting microorganism and their resistance

Table 5 Summary of antibiotic suitability profiles according to Antibiotic Use Guideline Hospital (2018) [19] and ASHP Therapeutic Guidelines (2014) [6]

\begin{tabular}{|c|c|c|c|c|c|c|c|c|c|c|}
\hline \multirow[t]{2}{*}{ Surgical procedures } & \multicolumn{2}{|c|}{$\%$ right type } & \multicolumn{2}{|c|}{$\%$ right time } & \multicolumn{2}{|c|}{$\%$ right dose } & \multicolumn{2}{|c|}{$\%$ right duration } & \multicolumn{2}{|c|}{$\%$ right route } \\
\hline & AUGH & ASHP & AUGH & ASHP & AUGH & ASHP & AUGH & ASHP & AUGH & ASHP \\
\hline Herniotomy $(\mathrm{n}=18)$ & 0 & 0 & 0 & 11.11 & 0 & 0 & 0 & 0 & 0 & 100 \\
\hline AV shunt $(n=18)$ & 5.56 & 5.56 & 11.11 & 11.11 & 5.56 & 5.56 & 11.11 & 11.11 & 27.78 & 27.78 \\
\hline Myomectomy $(n=14)$ & 0 & 0 & 50 & 50 & 0 & 0 & 21.43 & 21.43 & 100 & 100 \\
\hline Mammary tumor excision $(n=8)$ & 50 & 50 & 75 & 75 & 50 & 50 & 37.5 & 37.5 & 100 & 100 \\
\hline AFF plate $(n=7)$ & 14.29 & 14.29 & 85.71 & 85.71 & 14.29 & 14.29 & 28.57 & 28.57 & 100 & 100 \\
\hline Tumor excision $(\mathrm{n}=7)$ & 14.29 & 28.57 & 42.86 & 42.86 & 14.29 & 28.57 & 14.29 & 14.29 & 100 & 100 \\
\hline Soft tissue tumor excision $(n=6)$ & 16.67 & 16.67 & 50 & 50 & 16.67 & 16.67 & 66.67 & 66.67 & 100 & 100 \\
\hline Thyroidectomy $(\mathrm{n}=5)$ & 100 & 100 & 80 & 80 & 100 & 100 & 60 & 60 & 100 & 100 \\
\hline Axillary tumor excision $(n=5)$ & 0 & 0 & 20 & 20 & 0 & 0 & 0 & 0 & 100 & 100 \\
\hline Caesarean section $(n=4)$ & 50 & 25 & 50 & 50 & 25 & 0 & 50 & 50 & 100 & 100 \\
\hline Mastectomy $(\mathrm{n}=2)$ & 0 & 0 & 0 & 0 & 0 & 0 & 50 & 50 & 100 & 100 \\
\hline Cholecystectomy $(\mathrm{n}=23)$ & 60.87 & 4.35 & 43.48 & 43.48 & 60.87 & 4.35 & 8.7 & 8.7 & 100 & 100 \\
\hline Appendectomy $(\mathrm{n}=17)$ & 64.71 & 0 & 41.18 & 41.18 & 58.82 & 0 & 11.76 & 11.76 & 100 & 100 \\
\hline URS $(n=9)$ & 0 & 0 & 70 & 80 & 0 & 0 & 20 & 20 & 100 & 100 \\
\hline TURB $(n=4)$ & 25 & 25 & 75 & 75 & 25 & 25 & 0 & 0 & 100 & 100 \\
\hline Colonoscopy $(n=4)$ & 0 & 0 & 66.67 & 66.67 & 0 & 0 & 0 & 0 & 100 & 100 \\
\hline Hepatoscopy $(n=2)$ & 100 & 100 & 100 & 100 & 100 & 100 & 0 & 0 & 100 & 100 \\
\hline Whipple procedure $(\mathrm{n}=1)$ & 0 & 0 & 0 & 0 & 0 & 0 & 0 & 0 & 100 & 100 \\
\hline Abscess drainage-incision $(n=5)$ & 0 & 0 & 100 & 100 & 0 & 0 & 20 & 20 & 100 & 100 \\
\hline Fistulectomy $(n=4)$ & 50 & 0 & 50 & 50 & 50 & 0 & 0 & 0 & 100 & 100 \\
\hline Post appendicitis excision $(n=1)$ & 0 & 0 & 100 & 100 & 0 & 0 & 0 & 0 & 100 & 100 \\
\hline Average & 26.26 & 17.59 & 52.91 & 53.38 & 24.79 & 16.4 & 19.05 & 19.05 & 91.8 & 96.56 \\
\hline
\end{tabular}

$A U G H$ Antibiotic Use Guideline Hospital $A S H P$ American Society of Health-System Pharmacists $A V$ arteriovenous, $A F F$ atypical femoral fractures, $U R S$ ureteroscopy, TURB transurethral resection of a bladder 
patterns have not been compared between Indonesia and the USA for all operations and this is discussed below.

Prophylactic antibiotics must have bactericidal properties and be effective against aerobic and anaerobic pathogens that are most likely to contaminate surgical areas, such as Staphylococcus and Streptococcus on the skin, coliforms (Escherichia coli and similar organisms), and normal flora found in the incised skin [23, 24]. Inappropriate use of prophylactic antibiotics can reduce the effectiveness of antibiotics, increase the risk of surgical site infection, and the incidence of antibiotic resistance [25].

\section{The qualitative evaluation}

\section{Choice of antibiotic}

The choice of antibiotic depends on the type of surgery. Cholecystectomy, one of the most common procedures, is the surgical removal of gallstones and is classified as a clean-contaminated surgery. According to Antibiotic Use Guideline Hospital (2018), the first-choice prophylactic antibiotic for cholecystectomy is ceftriaxone, but ASHP Therapeutic Guidelines recommends cefazolin $[6,19]$. Moazeni and Imani [26] prepared bacterial cultures from patients with cholelithiasis and found that the most identified microorganism was E. coli. Similarly, Soman et al. [27] also categorized E. coli as the most frequently isolated organism; the third-generation cephalosporin, ceftriaxone, is suitable for its effectiveness against gram-negative bacteria like E. coli [27]. Ceftriaxone also has a long half-life, 5-9 h, which means that a certain bactericidal level of antibiotic is sustained during a surgical procedure, and accordingly, the administration of additional doses for long-term surgeries is unnecessary [28].

Another very common surgical procedure was AV shunt insertion but of the 18 patients receiving it, 13 were not given prophylactic antibiotics. Antibiotic Use Guideline Hospital and ASHP Therapeutic Guidelines recommend the administration of cefazolin but only one patient received it. A retrospective study by Gray et al. [29] found that 244 of 294 patients (83\%) undergoing arteriovenous fistula (AVF) and arteriovenous graft (AVG) from November 2014 to July 2016 received prophylactic antibiotics, and two of those patients experienced surgical site infection $(0.68 \%)$ [29]. Since the incidence of surgical site infection in patients receiving and not receiving prophylactic antibiotics during the AV Shunt procedure is not significantly different, most surgeons at the study hospital do not practice antibiotic prophylaxis for this surgery.

In this study, 18 patients (11.0\%) undergoing hernia surgeries received prophylactic antibiotics without any indications stated in the Antibiotic Use Guideline Hospital. This result is $0 \%(0 / 18)$ in conformity to Antibiotic Use Guideline
Hospital and ASHP Therapeutic Guidelines, respectively. Through a meta-analysis study, Sanchez-Manuel et al. (2012) observed 7843 patients with hernias (4703 were given prophylactic antibiotics, but 3140 were not) and found that the incidence of infection occurred in $3.1 \%$ of the prophylactic group and $4.5 \%$ of the control group (OR 0.64; 95\% CI 0.50-0.82) [30].

\section{Timing of administration}

Information on the right timing of antibiotic administration is essential as it can ensure that the antibiotics present in serum and tissue can reach the target during the surgery [31]. The recommended time for antibiotic use based on Antibiotic Use Guideline Hospital and ASHP Therapeutic Guidelines is less than $60 \mathrm{~min}$ before the incision, or less than $120 \mathrm{~min}$ if vancomycin or fluoroquinolones are used [6]. Of 164 patients in this study, 52.9\% conformed to the Antibiotic Use Guideline Hospital and 53.6\% to ASHP Therapeutic Guidelines, with a majority of antibiotics administered 60-120 min before the incision (55 patients, 37\%). Inappropriate timing of antibiotics can increase surgical site infection, as proven in a retrospective cohort study by Hwan et al. (2013). They analyzed 32,459 surgeries consisting of orthopedic, colorectal, vascular, and gynecological surgical procedures from 2005 to 2009 in 112 hospitals and found that the surgical site infection incidence rate was higher when prophylactic antibiotics were administered longer than $60 \mathrm{~min}$ before the incision (OR 1.34; 95\% CI 1.08-1.66) compared with an administration within $60 \mathrm{~min}$ before incision (OR 1.26; 95\% CI $0.92-1.72)$ [32].

\section{Dosage selection}

The dose of antibiotics is determined by factoring in the pharmacokinetic profile of antibiotics and patient conditions, such as body weight, to ensure that the concentration of antibiotics in serum and tissue is adequate for surgical prophylaxis [6,33]. According to Antibiotic Use Guideline Hospital, the recommended dosage varies depending on the type of surgical procedure, but is generally $1 \mathrm{~g}$ of ceftriaxone or $1 \mathrm{~g}$ of cefazolin. According to ASHP Therapeutic Guidelines, the recommended dosage of ceftriaxone in adults is $2 \mathrm{~g}$, or $2 \mathrm{~g}$ cefazolin and $3 \mathrm{~g}$ cefazolin for patients weighing $\geq 120 \mathrm{~kg}$. Since the patients sampled in this study did not weigh $\geq 120 \mathrm{~kg}$, the dose used for cefazolin was $2 \mathrm{~g}$ [19]. 


\section{Duration of prophylaxis}

Prophylactic antibiotics are given in a duration of no longer than $24 \mathrm{~h}$, except for cardiothoracic procedures where up to $48 \mathrm{~h}$ is allowable [6]. Most patients in this study (80\%) used antibiotics for more than $24 \mathrm{~h}$. There were 17 patients (11\%) who received antibiotics from the time of admission to the hospital until they were about to be discharged. Seventeen of these patients underwent cholecysctectomy, appendectomy, colonoscopy, hepatoscopy, and TURB, none of which required antibiotics $>24 \mathrm{~h}$. Of the 149 patients who used antibiotics, the right duration based on the Antibiotic Use Guideline Hospital and ASHP Therapeutic Guidelines was found in $19.1 \%$ and $18.4 \%$, respectively. Branch-Elliman et al. [34] observed 79,058 patients who underwent heart surgery, orthopedic joint replacement, colorectal surgery, and vascular surgery from 2008 to 2013 and found that the relative risks of postoperative Clostridium difficile infection in non-cardiac surgery where prophylactic antibiotics were administered for 24 to $<48 \mathrm{~h}, 48$ to $<72 \mathrm{~h}$, and $>72 \mathrm{~h}$ were 1.31 (95\% CI 1.21-1.42), 1.72 (95\% CI 1.47-2.01), and 1.79 (95\% CI 1.27-2.53) compared to <24 h [34].

\section{Route of administration}

Based on the Antibiotic Use Guideline Hospital and ASHP Therapeutic Guidelines, the recommended route of surgical prophylactic antibiotics is intravenous because it has a rapid onset of reaction and its levels in blood and tissue can be predicted [6].

Overall, this study identified inappropriate antibiotic prescribing: duration $(81,0 \%)$, dose $(75,2 \%)$, choice of antibiotic (73.7\%), time of giving (47.1\%), and route (8.2\%); compared to The Hospital National Antimicrobial Prescribing Survey (2016) in Australia, that found improper duration (29.9\%), wrong dosage (27.6\%), and procedures that did not require antibiotics (22.0\%) [35].

The high rate of antibiotic use that did not comply with the Antibiotic Use Guideline Hospital shows the lack of agreement between surgeons and the Antibiotic Use Guideline Hospital. This finding is similar to Soman et al. [27], who found that non-compliance with the hospital's antibiotic policy was up to 50.4\% [26]. Aly et al. [36] found that adherence to selection, dosage, route, frequency, and duration of antibiotics was only $30.4 \%$. Reasons for prescribing surgical prophylaxis without an approved indication included fears of complications, a greater confidence from the surgeon when the patient received antibiotics, or surgeons who disagreed with the guidelines [36].

\section{Limitations}

The limitation of this study lies in its retrospective design that collected data from available medical records. Hence, patients who met the inclusion and exclusion criteria but had incomplete medical record records had to be excluded. Also, inappropriate antibiotic selection may indicate that surgeons disagree with the current Antibiotic Use Guideline Hospital, which also refers to ASHP Therapeutic Guidelines. For this reason, the use of antibiotics preferred by surgeons and proposed by Antibiotic Use Guideline must be in agreement, and only then, will every surgeon comply with the Antibiotic Use Guideline.

\section{Conclusion}

Based on the quantity, ceftriaxone was the first-choice prophylactic antibiotic administered to patients registered at a private hospital in Surabaya between January and June 2019 even though often this did not conform to guidelines for the use of antibiotics in hospitals as well as international guidelines. It is necessary to carry out further research regarding the factors that influence the prescribing of antibiotics by the surgeon and the impact of the inappropriate use of antibiotics.

Acknowledgements The authors would like to thank the Director of the Private Hospital for allowing us to conduct research in their hospital. We would like to thank David Scott, Pharmacy Department, Cardiff University, UK for reviewing, editing and proofreading the manuscript.

Funding This research received a grant from the Ministry of Research, Technology, and Higher Education of the Republic of Indonesia No. 036/SP-Lit/LPPM-01/RistekBRIN/Mono/FF/III/2020.

Conflicts of interest The authors declared no potential conflicts of interest with respect to the research, authorship, and/or publication of this article.

\section{References}

1. National Institute for Health and Care Excellence. Surgical site infections: prevention and treatment. NICE Guidel NG125. 2019. www.nice.org.uk/guidance/ng125. ISBN: 978-1-4731-3394-5.

2. Hall C, Allen J, Barlow G. Antibiotic prophylaxis. Surgery. 2012;30(12):651-8.

3. Dryden M. Surgical antibiotic prophylaxis. Surg (UK). 2019;37(1):19-25.

4. Mi K. Rational use of antibiotics in surgical practice. Bangladesh J Med Sci. 2017;16(04):483-6.

5. Alemkere G. Antibiotic usage in surgical prophylaxis: a prospective observational study in the surgical ward of Nekemte referral hospital. PLoS ONE. 2018;13(9):1-17. 
6. Bratzler DW, Dellinger EP, Olsen KM, Perl TM, Auwaerter PG, Bolon MK, et al. Clinical practice guidelines for antimicrobial prophylaxis in surgery. Am J Heal Pharm. 2013;70(3):195-283.

7. Australian Commission on Safety and Quality in Health Care. Antimicrobial Prescribing Practice in Australian Hospital: Results of the 2018 Hospital National Antimicrobial Prescribing Survey. 2020. ISBN: 978-1-925948-16-5.

8. Ierano C, Manski-Nankervis J-A, James R, Rajkhowa A, Peel T, Thursky K. Surgical antimicrobial prophylaxis. Aust Prescr. 2017;40(6):225-9.

9. Hakanen A, Jalava J, Kaartinen L. National Action Plan on Antimicrobial Resistance 2017-2021. Minist Soc Aff Heal. 2017. ISBN: 978-9-520039-65-3.

10. World Health Organization. Antimicrobial Resistance: Global Report on Surveillance. 2014. ISBN 978-92-4-156474-8.

11. World Health Organization. Global Action Plan on Antimicrobial Resistance. 2015. ISBN 978-92-4-150976-3.

12. World Health Organization. Ten threats to global health in 2019. 2019. https://www.who.int/news-room/spotlight/ten-threats-toglobal-health-in-2019. Accessed 10 Dec 2020.

13. Hospital Accreditation Commission (Komisi Akreditasi Rumah Sakit). Standar Nasional Akreditasi Rumah Sakit Edisi 1[National Accreditation Standards Hospital Edition 1]. 2018;1-421.

14. Minister of Health of the Republic of Indonesia (Menteri Kesehatan Republik Indonesia). Republic of Indonesia Minister of Health Regulation No. 8 concerning Antimicrobial Resistance Control Program in Hospitals [Peraturan Menteri Kesehatan RI Nomor 8 tentang Program Pengendalian Resistensi Antimikroba di Rumah Sakit]. 2015.

15. Minister of Health of the Republic of Indonesia (Menteri Kesehatan Republik Indonesia). RI Minister of Health Regulation No. 2406/MENKES/PER/XII/2011 concerning General Guidelines for the Use of Antibiotics [Peraturan Menteri Kesehatan RI Nomor 2406/MENKES/PER/XII/2011 tentang Pedoman Umum Penggunaan Antibiotik]. 2011.

16. World Health Organization. Antimicrobial Stewardship Programmes in Health-care Facilities in Low and Middle-Income Countries. 2019. ISBN 978-92-4-151548-1.

17. Scottish Intercollegiate Guidelines Network. Antibiotic Prophylaxis in Surgery: A National Clinical Guideline. 2014. ISBN 978-1-905813-34-6.

18. McLatchie G, Borley N, Chikwe J. Oxford Handbook of Clinical Surgery. 4th ed. Oxford: Oxford University Press; 2013. ISBN 978-0199699-47-6.

19. Tetanto P, Handini LS, Dewanto DD, Wijaya K, Bakhriansyah J, Pramesthi E, et al. Guide to the use of prophylactic and therapeutic antibiotics [Panduan Penggunaan Antibiotik Profilaksis dan Terapi]. 1st ed. 2018.

20. The State of Victoria and the Department of Health \& Human Services. Surgery. 2021. https://www.betterhealth.vic.gov.au/healt h/conditionsandtreatments/surgery. Accessed 3 Jan 2020.

21. Pratama NYI, Suprapti B, Ardhiansyah AO, Shinta DW. Analisis Penggunaan Antibiotik pada Pasien Rawat Inap Bedah dengan Menggunakan Defined Daily Dose dan Drug Utilization 90\% di Rumah Sakit Universitas Airlangga. Indones J Clin Pharm. 2019;8(4):256.

22. Herawati F, Yulia R, Hak E, Hartono AH, Michiels T, Woerdenbag HJ, Avanti C. A Retrospective surveillance of the antibiotics prophylactic use of surgical procedures in private hospitals in Indonesia. Hosp Pharm. 2019;54(5):323-9.

23. Global Alliance for Infections in Surgery Working Group. A global declaration on appropriate use of antimicrobial agents across the surgical pathway. Surg Infect. 2017;18(8):849-53.

24. Sartelli M, Duane TM, Catena F, Tessier JM, Coccolini F, Kao LS, et al. Antimicrobial stewardship: a call to action for surgeons. Surg Infect. 2016;17(6):625-31.

25. Abubakar U, Syed Sulaiman SA, Adesiyun AG. Utilization of surgical antibiotic prophylaxis for obstetrics and gynaecology surgeries in Northern Nigeria. Int J Clin Pharm. 2018;40(5):1037-43.

26. Moazeni Bistgani M, Imani R. Bacteria isolated from patients with cholelithiasis and their antibacterial susceptibility pattern. Iran Red Crescent Med J. 2013;15(8):759-61.

27. Soman N, Panda BK, Banerjee JK, John SM. A study on prescribing pattern of cephalosporins utilization and its compliance towards the hospital antibiotic policy in surgery ward of a tertiary care teaching hospital in India. Int Surg J. 2019;6(10):3614.

28. American Pharmacist Association. Drug Information Handbook. 27th ed. USA: Lexicomp; 2018. ISBN: 978-1-591953-70-8.

29. Gray K, Korn A, Zane J, Alipour H, Kaji A, Bowens N, et al. Preoperative antibiotics for dialysis access surgery: are they necessary. Ann Vasc Surg. 2018;49:277-80.

30. Sachez-Manuel FJ, Lozano-Garcia J, Seco-Gil JL. Antibiotic prophylaxis for hernia repair. Cochrane Database of Systematic Reviews. Cochrane Collab. 2012. https://doi.org/10.1002/14651 858.CD003769.pub4

31. World Health Organization. Global Guidelines for the Prevention of Surgical Site Infection. World Health Organization. 2018. ISBN 978-92-4-155047-5.

32. Hawn MT, Richman JS, Vick CC, Deierhoi RJ, Graham LA, Henderson WG, et al. Timing of surgical antibiotic prophylaxis and the risk of surgical site infection. JAMA Surg. 2013;148(7):649-57.

33. Hwan MT, Knowlton LM. Balancing the risks and benefits of surgical prophylaxis timing and duration do matter. Am Med Assoc. 2019;154(7):598-9.

34. Branch-Elliman W, O'Brien W, Strymish J, Itani K, Wyatt C, Gupta K. Association of duration and type of surgical prophylaxis with antimicrobial-associated adverse events. JAMA Surg. 2019;154(7):590-8.

35. Australian Commission on Safety and Quality in Health Care. Antimicrobial prescribing practice in Australian hospitals. 2016. ISBN: 978-1-925224-99-3.

36. Aly NY, Omar AA, Badawy DA, Al-Mousa HH, Sadek AA. Audit of physicians' adherence to the antibiotic policy guidelines in Kuwait. Med Princ Pract. 2012;21(4):310-7.

Publisher's Note Springer Nature remains neutral with regard to jurisdictional claims in published maps and institutional affiliations. 
- IJCP is a bi-monthly, international, peer-reviewed journal that publishes original research data, new ideas and discussions on a broad range of topics related to clinical pharmacy. See 'Aims and scope' for more information.

- IJCP publishes original Research articles, Review articles, Short research reports, Commentaries, Book reviews, Letters to the Editor and Editorials.

- show all

\section{Editor-in-Chief}

Derek Stewart

\section{Publishing model}

Hybrid (Transformative Journal). Learn about publishing_Open Access with us

1.616 (2019)

Impact factor

2.054 (2019)

Five year impact factor

\section{6 days}

Submission to first decision

190 days

Submission to acceptance
408,289 (2020)

Downloads 


\section{International Journal of Clinical Pharmacy}

COUNTRY

Netherlands

Universities and research

institutions in Netherlands
SUBJECT AREA AND CATEGORY

Health Professions

Pharmacy

Medicine

Pharmacology (medical)

Pharmacology, Toxicology and Pharmaceutics Pharmaceutical Science

Pharmacology

Toxicology
PUBLISHER

Springer Netherlan ds

Ads by Google

Stop seeing this ad Why this ad 


\title{
Download the Secure Browser
}

\author{
Google
}

SCOPE

The aim of International Journal of Clinical Pharmacy is to provide a medium for the publication of articles on clinical pharmacy al oriented subjects in the pharmaceutical sciences. The scope of the journal is clinical pharmacy, its research and its application in care. The editors therefore welcome contributions on the above-mentioned topics and especially on the following: • Pharmacother research $\cdot$ Clinical pharmacy $\cdot$ Pharmacoepidemiology $\cdot$ Pharmacoeconomics $\cdot$ Pharmaceutical care $\cdot$ Medicines and medical devi Medicines and medical devices information • Pharmacy services research • Medication management $•$ Other clinical aspects of pr welcomes papers in the following categories: Review articles, Research articles, Short research reports, Commentaries, ESCP bes and Letters to the Editor. Case reports are not considered for publication. All submissions (including Commentaries and, if necess peer-reviewed by experts. This is a single blinded procedure.

\section{di MISUMI Indonesia}

Dapatkan diskon hingga 15\% sekarang juga! Hanya sampai $21 \mathrm{Se}$ 2021 
2

International Journal of

Journal of Pharmaceutical Health Services Research GBR

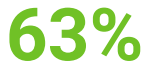

similarity

\section{Pharmacy Practice}

GBR

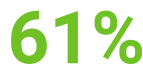

similarity
3

European Journal of Hospital Pharmacy

BEL

Research in Administrati USA

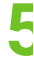

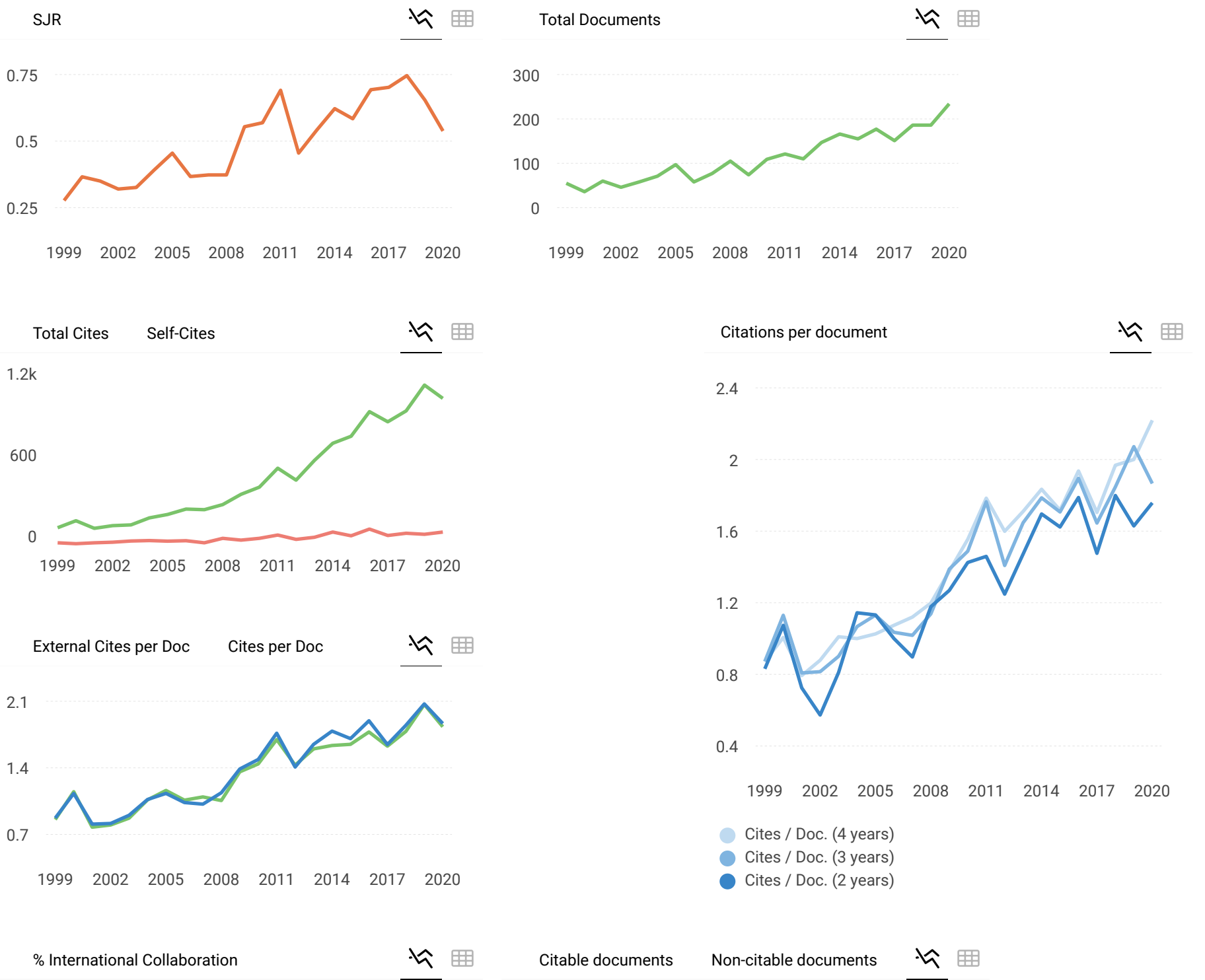


30

20

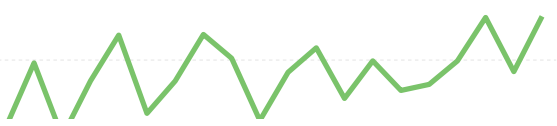

Cited documents Uncited documents

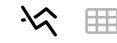

600

300

0

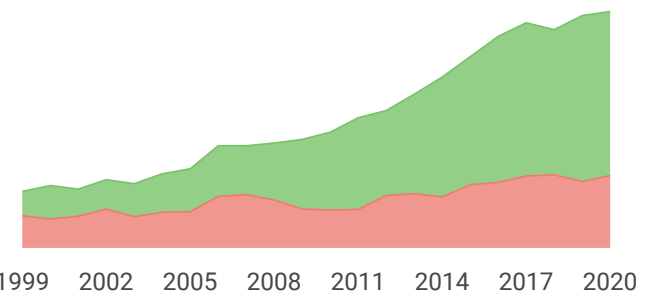

600

300

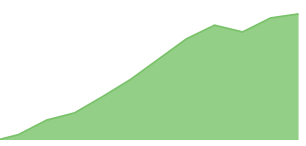

$\leftarrow$ Show this widget in your own website

Clinical Pharmacy

Pharmacy

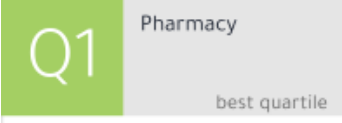

SJR 2020

0.54

powered by scimagojr.com
Just copy the code below and paste within your html code:

$<a$ href="https://www.scimas

\section{G SClmago Graphica}

Explore, visually communicate and make sense of data with our new free tool.

Get it

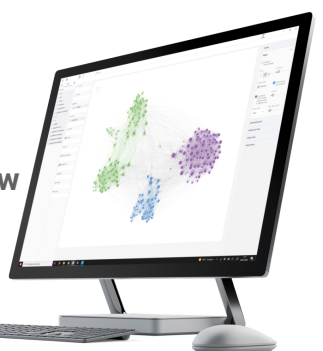

Ismaila Adamu 9 months ago

I will like to know the price for printed copy of this journal

reply

Melanie Ortiz 9 months ago

Dear Ismaila, thank you very much for your comment. Unfortunately, we cannot help you with your request, we suggest you contact the journal's editorial staff so they could inform you more deeply. Best Regards, SCImago Team 
$\mathrm{H} \quad$ Huda 2 years ago

Does this journal publish protocols of randomised controlled trials?

reply

Melanie Ortiz 2 years ago

Dear Huda,

thank you for contacting us.

Sorry to tell you that SCImago Journal \& Country Rank is not a journal. SJR is a portal with scientometric indicators of journals indexed in Elsevier/Scopus.

Unfortunately, we cannot help you with your request, we suggest you to visit the journal's homepage or contact the journal's editorial staff, so they could inform you more deeply. Best Regards, SCImago Team

\section{A Ana Braga 2 years ago}

Are there submission fees for this journal?

reply

Melanie Ortiz 2 years ago

Dear Ana,

thank you for contacting us.

Sorry to tell you that SCImago Journal \& Country Rank is not a journal. SJR is a portal with scientometric indicators of journals indexed in Elsevier/Scopus.

Unfortunately, we cannot help you with your request, we suggest you to visit the journal's homepage. Best Regards, SCImago Team

\section{Z Zahra 2 years ago}

Is the journal indexed in PubMed and Scopus

reply

Melanie Ortiz 2 years ago

Dear Zahra, thank you very much for your comment, unfortunately we cannot help you with your request. We suggest you to consult the Scopus database directly. Remember that the SJR is a static image of a database (Scopus) which is changing every day. Best regards, SCImago Team 
Good day. I would like to print an article in your magazine ....

I would like to know if you are printing an article and what requirements to the article, and what price article?

Thank you.

Good day for you.

reply

Elena Corera 3 years ago

Dear Taras, in the link below you will find the information corresponding to the author's instructions of this journal. Best regards, SCImago Team

http://www.editorialmanager.com/ijcp/default.aspx

\section{Leave a comment}

\section{Name}

Email

(will not be published)

Saya bukan robot

reCAPTCHA

Privasi - Persyaratan

Submit

The users of Scimago Journal \& Country Rank have the possibility to dialogue through comments linked to a specific journal. The purpose is to have a forum in which general doubts about the processes of publication in the journal, experiences and other issues derived from the publication of papers are resolved. For topics on particular articles, maintain the dialogue through the usual channels with your editor.

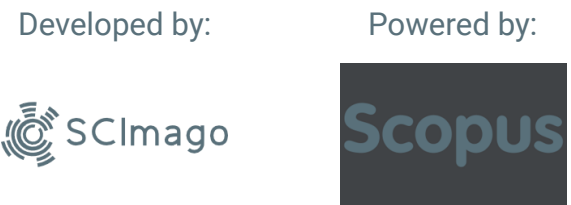


Follow us on @ScimagoJR

Scimago Lab, Copyright 2007-2020. Data Source: Scopus ${ }^{\circledR}$

EST MODUS IN REBUS

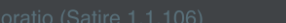




\section{Source details}

\section{International Journal of Clinical Pharmacy}

Formerly known as: Pharmacy World and Science

Scopus coverage years: from 2011 to Present

Publisher: Springer Nature

ISSN: 2210-7703 E-ISSN: 2210-7711

Subject area: Health Professions: Pharmacy Pharmacology, Toxicology and Pharmaceutics: Pharmaceutical Science

Medicine: Pharmacology (medical) Pharmacology, Toxicology and Pharmaceutics: Pharmacology

Pharmacology, Toxicology and Pharmaceutics: Toxicology
CiteScore 2020

2.7

SJR 2020

0.538

SNIP 2020

0.974 (i)

(i)

(i)

Source type: Journal
View all documents >
Set document alert
$\square$ Save to source list

\section{CiteScore CiteScore rank \& trend Scopus content coverage}

i Improved CiteScore methodology

CiteScore 2020 counts the citations received in 2017-2020 to articles, reviews, conference papers, book chapters and data papers published in 2017-2020, and divides this by the number of publications published in 2017-2020. Learn more >

\section{CiteScore 2020 \\ $2.7=\frac{1.699 \text { Citations } 2017-2020}{627 \text { Documents } 2017-2020}$}

Calculated on 05 May, 2021
CiteScoreTracker 2021 (1)

$$
2.6=\frac{1.449 \text { Citations to date }}{561 \text { Documents to date }}
$$

Last updated on 04 July, 2021 • Updated monthly

CiteScore rank 2020 (i)

\begin{tabular}{lrr} 
Category & Rank & Percentile \\
\hline Health Professions & & \\
$\begin{array}{l}\text { L Pharmacy } \\
\text { Pharmacology, }\end{array}$ & \\
$\begin{array}{l}\text { Toxicology and } \\
\text { Pharmaceutics } \\
L \text { Pharmaceutical } \\
\quad \text { Science }\end{array}$ & $\# 78 / 166$ & \\
\end{tabular}

View CiteScore methodology $>$ CiteScore FAQ $>$ Add CiteScore to your site $\mathbb{O}$

$\begin{array}{lll}\text { About Scopus } & \text { Language } & \text { Customer Service } \\ \text { What is Scopus } & \text { 日本語に切り替える } & \text { Help } \\ \text { Content coverage } & \text { 切换到简体中文 } & \text { Contact us } \\ \text { Scopus blog } & \text { 切換到繁體中文 } & \\ \text { Scopus API } & \text { Русский язык } & \\ \text { Privacy matters } & \text { 9з木 } & \end{array}$




\section{Editors}

Editor-in-Chief

Derek Stewart

Qatar University, Qatar

\section{Associate Editors}

Filipa Alves da Costa, ISCSEM, Portugal

Yolande Hanssens, Hamad Medical Corporation, Qatar

Vibhu Paudyal, University of Birmingham, UK

Shusen Sun, Western New England University, USA

\section{Editorial Board}

Lise Aagaard, Havemann, Denmark

Anna Birna Almarsdottir, University of Copenhagen, Denmark

Wiwat Arkaravichien, Khon Kaen University, Thailand

Isabelle Arnet, Pharmazentrum, Switzerland

Parisa Aslani, University of Sydney, Australia

Paolo Baldo, National Cancer Institute, Italy 
Hendrikus Boersma, University Medical Center Groningen, The Netherlands

Ian Boyd, Milton, Australia

Carolyn Coulter, Dunedin Hospital, New Zealand

Peter Dieleman, University of Antwerp, Belgium

Parastou Donyai, University of Reading, UK

Greg Duncan, Monash University, Australia

Roel Fijn, Diaconessenhuis Leiden, The Netherlands;

Linda Gore Martin, University of Wyoming, USA

Andy Gray, University of KwaZulu-Natal, South Africa

Anas Hamad, Hamad Medical Corporation, Qatar

Georg Hempel, Universitat Münster, Germany

Martin Henman, Trinity College Dublin, Ireland

Nejc Horvat, University of Ljubljana, Slovenia

Carmel Hughes, Queen's University Belfast, Northern Ireland

Chris Jay, Wellington, New Zealand

Frieder Keller, Universitatsklinikum Ulm, Germany

Imran Khudair, Hamad Medical Corporation, Qatar

Michelle King, Griffith University, Australia

Hannelore Kreckel, Universitätsklinikum Giessen und Marburg GmbH, Germany

Linda Lim, Brunei Darussalam

Angela Lupattelli, University of Oslo, Norway

Louise Mallet, Université de Montréal, Canada

Wandikayi Matowe, American University of the Caribbean School of Medicine, Sint Maarten

Giancarlo Nadin, Catholic University of the Sacred Heart, Italy

Adriano Max Reis, Universidade Federal de Minas Gerais, Brazil

Kati Sepponen, University of Eastern Finland, Finland

Win Winit-Watjana, International Medical University, Malaysia 


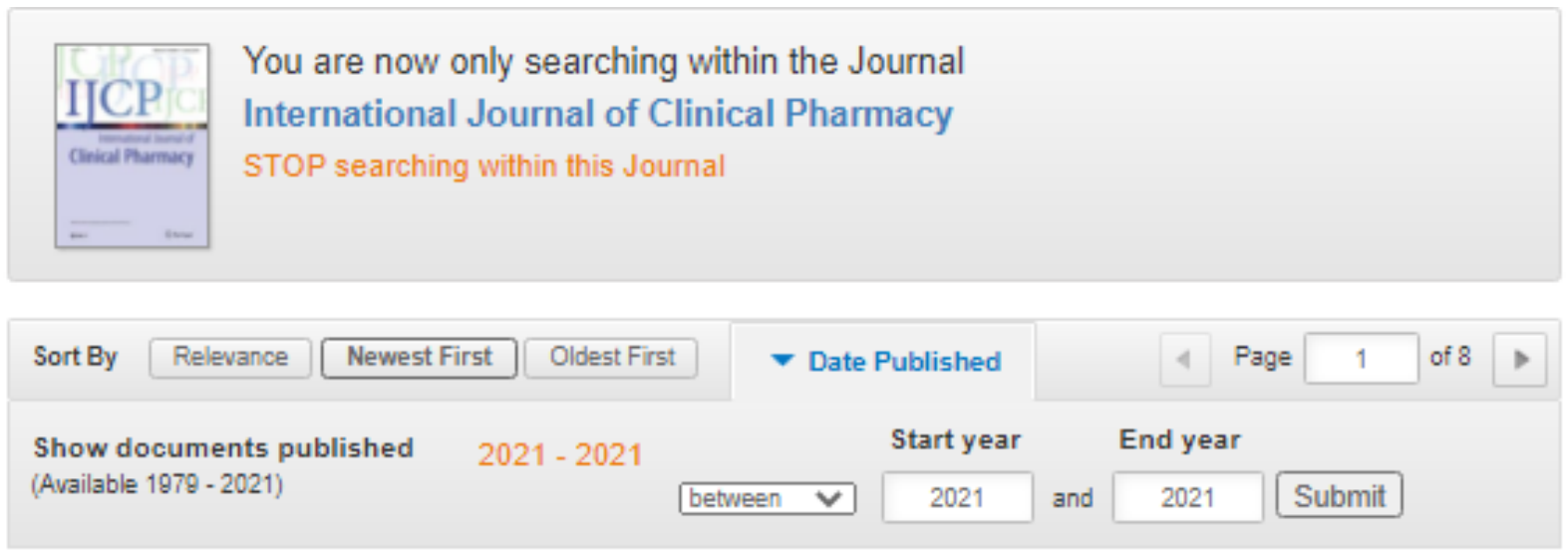

Article

A qualitative exploration of the healthcare challenges and pharmaceutical care needs of people with Parkinson's and their caregivers

Background People with Parkinson's are at higher risk of healthcare and pharmaceutical care issues. Objective To determine the healthcare challenges, pharmaceutical care needs, and perceived need of a pharmacist-...

Sabrina Anne Jacob. Zhi Jean Wong ... in Intemational Journal of Clinical Phamacy (2021)

„5 Download PDF (653 KB) ^. View Article

(Q) Article

Management of drug-disease interactions: a best practice from the Netherlands

Background Drug-disease interactions are situations where pharmacotherapy may have a negative effect on patients' comorbidities. In these cases, it can be necessary to avoid that drug, adjust its dose or monitor ...

Maaike M. E. Diesveld, Suzanne de Klerk... in Intemational Joumal of Clinical Phamacy (2021)

\section{Exploring pharmacist involvement in the discharge medicines} reconciliation process and information transfer to primary care: an observational study

Background Medication errors can occur because of incomplete or poorly communicated information at the transition from hospital to community. Following an audit in 2016, a project was undertaken to determine if p... Alison Hill, Michael Wilcock in Intemational Journal of Clinical Fharmacy (2021)

Article

Clinical pharmacists in Dutch general practice: an integrated care model to provide optimal pharmaceutical care

Background Medication-related harm is a major problem in healthcare. New models of integrated care are required to guarantee safe and efficient use of medication. Aim To prevent medication-related harm by integra...

Ankie Hazen, Vivianne Sloesenvij, Bart Pouls... in Intemational Journal of Clinical Phamacy (2021)

» Download PDF (663 KB) ^View Article 
Quantity and quality profiles of antibiotics pre, on, and post surgery in a hospital setting

Background Providing proper antibiotics is undoubtedly crucial to prevent infections during surgery. Objective This study set out to evaluate the medication administration in antibiotic prophylaxis using both qua... Nurlina Muliani, Fauna Herawati, Rika Yulia... in international Joumal of Clinical Pharmacy (2021)

Article

The current and potential role of community pharmacy in assetbased approaches to health and wellbeing: a qualitative study

Background Asset-based approaches seek to positively mobilise the strengths, capabilities, and resources of individuals and communities. To date, limited consideration has been given to the potential value of thi..

Jayne Astbury. Ellen Schafheutle, Jane Brown... in Intemational Joumal of Clinical Pharmacy (2021)

» Download PDF (592 KB) „ View Article

Article

Evaluation of pharmacists' interventions on drug-related problems and drug costs in patients with cancer pain

Drug-related problems (DRPs) prevent patients from fully benefiting from drug treatment. Unrelieved pain in patients with cancer is still widespread. Pharmacists can play a role in closely monitoring cancer pa...

Ping Zhang. Dan Lv, Jin Zhao, Shusen Sun... in International Journal of Clinical Phamacy (2021)

Article

Reducing corticosteroid phobia in pharmacy staff and parents of children with atopic dermatitis

Background Besides physicians, pharmacy staff has an important role to inform patients on appropriate medication use. However, they might also experience corticophobia themselves, affecting patient counseling and...

Ellen S. Koster, Daphne Philbert, Xiang Zheng... in Intemational Joumal of Clinical Phamacy (2021)

» Download PDF (876 KB) \& View Article 